\title{
TENDÊNCIAS E OPORTUNIDADES EM LÓGICAS INSTITUCIONAIS: UM ESTUDO BASEADO EM PAREAMENTO BIBLIOGRÁFICO
}

\author{
(iD Luis Miguel Zanin ${ }^{1}$ e ${ }^{\text {ID }}$ Julio Carneiro da Cunha ${ }^{2}$ \\ ${ }^{1}$ Universidade Nove de Julho, São Paulo, SP, Brasil.zanin@ @onquistar.com.br \\ ${ }^{2}$ Universidade Nove de Julho, São Paulo, SP, Brasil. juliocunha@uni9.pro.br
}

\section{Resumo}

Objetivo do Estudo: Analisar, por meio do pareamento bibliográfico, as possibilidades e oportunidades de estudos futuros em lógicas institucionais, com destaque às oportunidades para a área de estratégia.

Metodologia/Abordagem: Este é um estudo bibliométrico, no qual analisamos a produção em lógicas institucionais, por meio da técnica de pareamento bibliográfico.

Originalidade/Relevância: Lógicas institucionais são um desdobramento recente do neoinstitucionalismo e oferece uma oportunidade de estudos, indicando as principais possibilidades de contribuição tanto no tema das lógicas institucionais em si, quanto na relação com a estratégia.

Principais Resultados: Devido à maturidade da teoria neoinstitucional, as lógicas institucionais se apresentam, de certo modo, de forma coesa. No entanto, ao contrário do neoinstitucionalismo, apresenta-se como uma opção baseada na teoria institucional para explicar as mudanças e inovações, temas caros à estratégia.

Contribuições Teóricas/Metodológicas: Este trabalho apresenta três contribuições principais: a) indica quais temas dentro do campo estão mais maduros, como complexidade institucional, e quais são emergentes, como a hibridização e categorização como elemento de mudança institucional; b) mostra que os estudos em estratégia estão mais relacionados a lógicas institucionais, como a teoria do alto escalão e a tomada de decisão; e c) entrega acompanhamento objetivo do alinhamento da identidade e seu reflexo no desempenho da organização, a considerar as lógicas institucionais como elementos que direcionarão as tomadas de decisão da organização, inclusive sob o ponto de vista da estratégia como prática. Por último, sob o ponto de vista metodológico, este trabalho contribui por utilizar o pareamento bibliográfico.

Palavras-chave: Teoria Institucional. Lógicas Institucionais. Pareamento Bibliográfico.

\section{TRENDS AND OPORTUNITIES IN INSTITUTIONAL LOGICS: A STUDY BASED ON BIBLIOGRAPHIC COUPLING}

Abstract

Objective: Analyzing, through bibliographic coupling, possibilities and opportunities of future studies in institutional logics, highlighting opportunities for strategy and organization area.

Methodology/Approach: This is a bibliometric study which analyzes the production in institutional logics through the technique of bibliographic coupling.

Originality/Relevance: Institutional logics are a recent development of neoinstitutionalism and offer an opportunity for studies indicating the main possibilities for contribution both in the theme of the institutional logics itself, and in the relationship with strategy.

Main Results: Due to the maturity of the neo-institutional theory the institutional logics are, in a way, a cohesive path. However, unlike neoinstitutionalism, it presents itself as an option based on institutional theory to explain changes and innovations, which are important subjects to strategy.
Theoretical/Methodological Contributions: This paper presents three contributions: a) it indicates which themes within the field are more mature, such as institutional complexity, and which are emerging, such as hybridization and categorization as an element of institutional change: b) it shows that the studies in strategy are more related to institutional logics, such as the theory of upper echelon and the decision making; and c) it indicates other possibilities, from following the alignment of identity and its reflection on the performance of the organization to consider the institutional logics as elements that may guide the decision making process of organizations, including the point of view of strategy as practice. Finally, regarding method, this work contributes to the use of techniques of bibliographic coupling.

Keywords: Institutional Theory. Institutional Logics. Bibliographic Coupling.

TENDENCIAS Y OPORTUNIDADES EN LÓGICA INSTITUCIONAL: UN ESTUDIO BASADO EN EL ACOPLAMIENTO BIBLIOGRÁFICO

\begin{abstract}
Resumen
Objetivo: Analizar, a través del acoplamiento bibliográfico, las posibilidades y oportunidades de futuros estudios en lógicas institucionales, destacando las oportunidades para el área de estrategia. Metodología / Enfoque: Este fue un estudio bibliométrico, analizando la producción en lógicas institucionales a través de la técnica de acoplamiento bibliográfico.

Originalidad/relevancia: La lógica institucional se presenta como un desarrollo reciente del neoinstitucionalismo y ofrece una oportunidad para los estudios que indican las principales posibilidades de contribución tanto en el tema de la lógica institucional como en la relación de esta con la estrategia.

Principales resultados: Debido a la madurez de la teoría neoinstitucional, las lógicas institucionales se presentan, de alguna manera, de manera cohesiva. Sin embargo, a diferencia del neoinstitucionalismo, se presenta como una opción basada en la teoría institucional para explicar cambios e innovaciones, temas que son importantes para la estrategia.

Contribuciones teóricas/metodológicas: este documento presenta tres contribuciones, la primera indica qué temas dentro del campo son más maduros, como la complejidad institucional, y cuáles están surgiendo, como la hibridación y la categorización como un elemento de cambio institucional. La segunda contribución muestra que los estudios de estrategia están más relacionados con las lógicas institucionales, como la teoría del escalón superior y la toma de decisiones. Además, existen otras posibilidades, desde seguir de forma más objetiva la alineación de la identidad y su reflexión sobre el desempeño de la organización, hasta considerar las lógicas institucionales como elementos que guiarán la toma de decisiones de la organización, incluso desde el punto de vista. De la visión de la estrategia como práctica. Finalmente, desde el punto de vista metodológico, este trabajo contribuye al uso de la comparación bibliográfica.
\end{abstract}

Palabras clave: Teoría Institucional. Lógicas Institucionales. Acoplamiento Bibliográfico.

\section{Como citar}

American Psychological Association (APA)

Zanin, L. \& Cunha, J. (2020). Tendências e oportunidades em lógicas institucionais: um estudo baseado em pareamento bibliográfico. Iberoamerican Journal of Strategic Management (IJSM), 19(1), 04-32. https://doi.org/10.5585/riae.v19i1.13926. 


\section{Introdução}

Há alguns anos, a Teoria Institucional vem sendo utilizada para explicar fenômenos dentro da administração de empresas sob um ponto de vista sociológico. Em suas diversas vertentes, a Teoria Institucional já foi utilizada para explicar desde como as instituições fazem com que as organizações se assemelhem (Dimaggio \& Powell, 1983) até como fazem com que os mercados e organizações se modifiquem ao longo do tempo (Lounsbury, 2007; Pahnke, Katila, \& Eisenhardt, 2015). Este aumento recente de seu uso indica que é uma teoria importante, principalmente em sua vertente mais atual, utilizada para explicar a mudança e inovação dentro de um contexto com diversos atores interagindo entre si.

Podemos considerar as lógicas institucionais como crenças culturais e regras socialmente compartilhadas, que moldam a cognição e comportamento dos atores e que, deste modo, provêm significados para os símbolos e práticas socialmente compartilhados, fornecendo critérios para legitimação (Friedland \& Alford, 1991; Thornton, Ocasio, \& Lounsbury, 2012). Assim, complementando a teoria neoinstitucional, que foi mais utilizada para explicar as disseminação e replicações de práticas e a manutenção das instituições (DiMaggio \& Powell, 1983; Haveman, 1993; Meyer \& Rowan, 1977), as lógicas institucionais têm sido utilizadas também para explicar a disseminação de práticas. Além disso, essas lógicas explicam o surgimento de novas práticas, mudanças institucionais, surgimento de novas instituições, bem como a variação de comportamentos das organizações dentro de um mesmo campo institucional (Edman, 2016a; Greenwood et al., 2010; Lee \& Lounsbury, 2015).

Na perspectiva de mudanças, as lógicas institucionais também estão associadas a mudanças e evoluções de práticas dentro de um mesmo campo profissional (Currie \& Spyridonidis, 2016; Dunn \& Jones, 2010). Assim, as lógicas institucionais têm contribuído para explicar mudanças em diversos contextos, tais como no sistema educacional (Thornton \& Ocasio, 1999), na criação e surgimento de novas práticas em instituições financeiras (Almandoz, 2014), nas mudanças na educação e criação de identidades no sistema de saúde (Currie \& Spyridonidis, 2016; Dunn \& Jones, 2010), no surgimento e legitimação de novas práticas na gastronomia (Rao, Monin, \& Durand, 2003) e na criação de identidade organizacionais para responder a diversas lógicas intencionais (Kodeih \& Greenwood, 2014; Trish Reay \& Hinings, 2009).

Em campos com crescente produção acadêmica, como tem sido o caso das lógicas institucionais, é importante haver estudos e revisões que busquem mapear esta evolução, visto que ajudam à compreensão e à organização de conceitos e achados da área. Em relação à teoria institucional, muitas revisões vêm sendo feitas como, por exemplo, sobre o empreendedorismo institucional (Battilana, Leca, \& Boxenbaum, 2009), o decoupling (Bromley \& Powell, 2012), sobre como as organizações adotam formas organizacionais híbridas para responder a diversas demandas por legitimação (Battilana \& Lee, 2014), como as lógicas institucionais criam vocabulários e práticas organizacionais (Loewenstein, 
Ocasio, \& Jones, 2012) e como as organizacionais respondem a diversas lógicas, conflitantes ou não (Greenwood, Raynard, Kodeih, Micelotta, \& Lounsbury, 2011). Entretanto, embora seja um elemento comum a todos estes temas, poucos trabalhos revisaram, até então, estritamente o tema das lógicas. Dentre estes poucos trabalhos, merece destaque o capítulo de Thornton e Ocasio (2008). Além disso, o foco desses estudos tem sido as revisões teóricas que, ainda que possam garantir uma visão aprofundada sobre o tema, podem, por outro lado, carregarem vieses dos autores que estão altamente envolvidos no tema e, desta maneira, sofrerem alguma falta de vigor metodológico (Tranfield, Denyer, \& Smart, 2003; Vogel \& Güttel, 2013).

Há uma predominância dos mesmos autores e os mesmos periódicos nos exemplos citados. Essa concentração de conhecimentos, aliada à necessidade de organização do tema e à sua compreensão conceitual, faz com que seja importante haver um estudo bibliométrico capaz de auxiliar a estruturação do conhecimento dessa temática. Isso ocorre porque estudos bibliométricos utilizam métodos quantitativos para analisar determinadas áreas das ciências, temas, periódicos, trabalhos e autores. Dessa maneira, considera-se também a maneira como tais elementos se relacionam entre si, para se criarem representações gráficas desses resultados (Zupic \& Čater, 2015).

A maior parte dos estudos bibliométricos trata de análise de cocitação. Neste tipo de bibliometria, o objetivo é analisar a similaridade entre diferentes documentos quando estes são citados em conjuntos, de modo a se obter uma imagem do campo no passado (Zupic \& Čater, 2015). No entanto, neste trabalho, utilizou-se o pareamento, ou acoplamento bibliográfico que, ao contrário da cocitação, busca identificar trabalhos que compartilham uma mesma citação. Essa técnica possibilita a criação de um mapa de um determinado campo, o qual permite a análise da direção das pesquisas desse campo (Jarneving, 2007; Thijs, Zhang, \& Glänzel, 2015; Zupic \& Čater, 2015) e não apenas quais foram as principais referências no passado. Assim, este trabalho tem como objetivo analisar quais são as publicações em lógicas institucionais, indicando as possibilidades de estudos futuros para este campo. De modo a contribuir com o tema, este trabalho tem a seguinte questão de pesquisa: quais são as tendências e oportunidades de pesquisa em lógicas institucionais?

Este trabalho contém, além desta introdução, um breve referencial sobre lógicas institucionais, a apresentação do método, a apresentação dos dados, discussão, a conclusão e sugestões de estudos futuros.

\section{Método}

O método utilizado neste artigo é uma modalidade de análise bibliométrica. A bibliometria consiste no uso de métodos quantitativos para descrever, avaliar e acompanhar a produção científica (Zupic \& Čater, 2015). Na verdade, em sua origem, sua definição é mais abrangente, e consiste no uso de ferramentas estatística e matemáticas aplicadas, livros e outras formas de comunicação (Vogel \& Güttel, 2013). De qualquer modo, o objetivo dos estudos bibliométricos tem sido avaliar o desempenho 
de determinada área, periódicos, autores etc., além de mapear e descrever áreas do conhecimento e teorias, apresentando a estrutura e a dinâmica do campo ou área estudada (Zupic \& Čater, 2015).

O pareamento bibliográfico consiste na identificação de pares de trabalhos que citam uma ou mais obras (Vogel \& Güttel, 2013; Zupic \& Čater, 2015). Este método tem suas semelhanças com a análise de cocitação, pois ambos baseiam-se nos dados fornecidos na lista de referências citadas nas publicações analisadas (Glanzel \& Czerwon, 1996). No entanto, enquanto a cocitação apresenta a base de conhecimento subjacente a uma determinada área, já que parte da análise de autores que são citados em conjunto em um ou mais trabalhos, o pareamento bibliográfico tende a apresentar as fronteiras da pesquisa de um determinado tema (Zupic \& Čater, 2015). Esta relação é apresentada na Figura 1.

Figura 1 - Análise de cocitação e pareamento bibliográfico

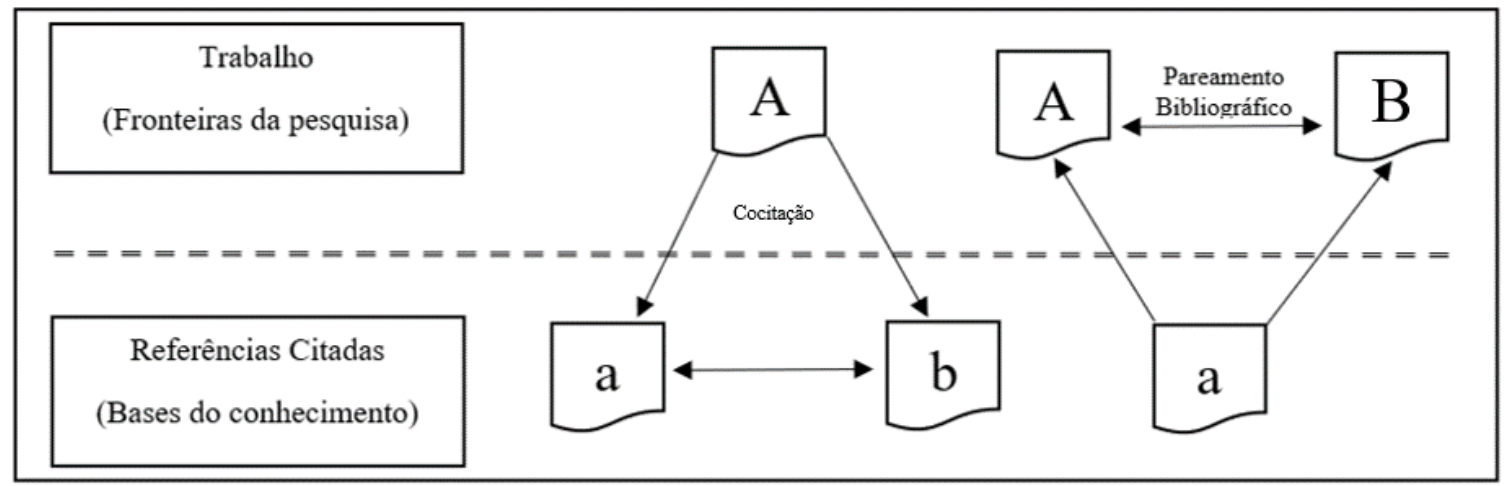

Fonte: Zupic e Čater (2015).

\subsection{Coleta de dados}

Os dados foram coletados em setembro de 2018, na base de dados Web of Science, da Thomson Reuters. A busca foi feita em todos os periódicos da base de dados das seguintes áreas: administração, negócios e administração pública. Esse foi o filtro aplicado, deixando explícita essa fase da pesquisa, tal como recomenda Quevedo-Silva et al. (2016). Além disso, como o surgimento do tema está mais relacionado à área de sociologia, esta área também foi incluída. Para essa busca, foram utilizadas as seguintes palavras-chave: "institutiona* logic*", "institutiona* order*”, "interinstitutional* order*". Todos estes termos foram buscados no campo tópico, ou seja, a busca foi feita tanto nos títulos quanto nos resumos e palavras-chave.

Estas palavras vão ao encontro dos principais termos utilizados, conforme os trabalhos de Friedland \& Alford (1991), Scott (2014) e Thornton e Ocasio (2008). O período examinado nesta busca foi de 1945 até 2017 e foram considerados apenas artigos científicos. A busca retornou 558 resultados e, após leitura dos resumos, restaram 537 artigos selecionados. 


\subsection{Preparação dos dados}

Para tratar os dados, utilizamos os softwares Bibexcel, VosViewer e Iramuteq. Deste modo, o arquivo gerado na busca na base Web of Science foi preparado conforme as especificações de Person, Danell e Schneider (2009). Dessas etapas iniciais trabalhadas no Bibexcel, foram gerados os dados para utilização no software VosViewer. A escolha desse software deveu-se ao seu foco na visualização de dados, bem como aos algoritmos utilizados para a geração do gráfico de pareamento (van Eck \& Waltman, 2010). Além disso, para analisar melhor os grupos formados, utilizou-se o software Iramuteq, que realizou uma análise de conteúdo quantitativa nos resumos dos artigos presentes na amostra que compuseram o pareamento bibliográfico. Essa análise teve como objetivo gerar categorias a posteriori, que mostrariam quais são os temas presentes nos resumos e como se relacionam hierarquicamente (Ratinaud \& Marchand, 2012; Reinert, 1990).

É importante ressaltar que o pareamento bibliográfico é uma análise baseada em referências. Sendo assim, uma das etapas de preparação dos dados foi a padronização das referências citadas, de modo que citações diferentes da mesma obra, por exemplo livros com ano de edições diferentes, fossem contadas como uma única obra. Após esta padronização, optou-se por gerar a rede de pareamento pelo software Bibexcel, sendo esta rede visualizada no VosViewer. Além disso, foi utilizado o algoritmo do próprio VosViewer para gerar os clusters, conforme Person et al. (2009).

\section{Resultados}

\subsection{Produção em lógicas institucionais}

Inicialmente, os dados apresentados se referem à produção sobre lógicas institucionais, sendo que estes dados são importantes para se verificar a importância e relevância do tema. A a Figura 2 descreve que a produção em lógicas institucionais vem apresentando um crescimento constante após 2012, havendo uma pequena queda de 2016 para 2017. 
Figura 2 - Quantidade de artigos por ano

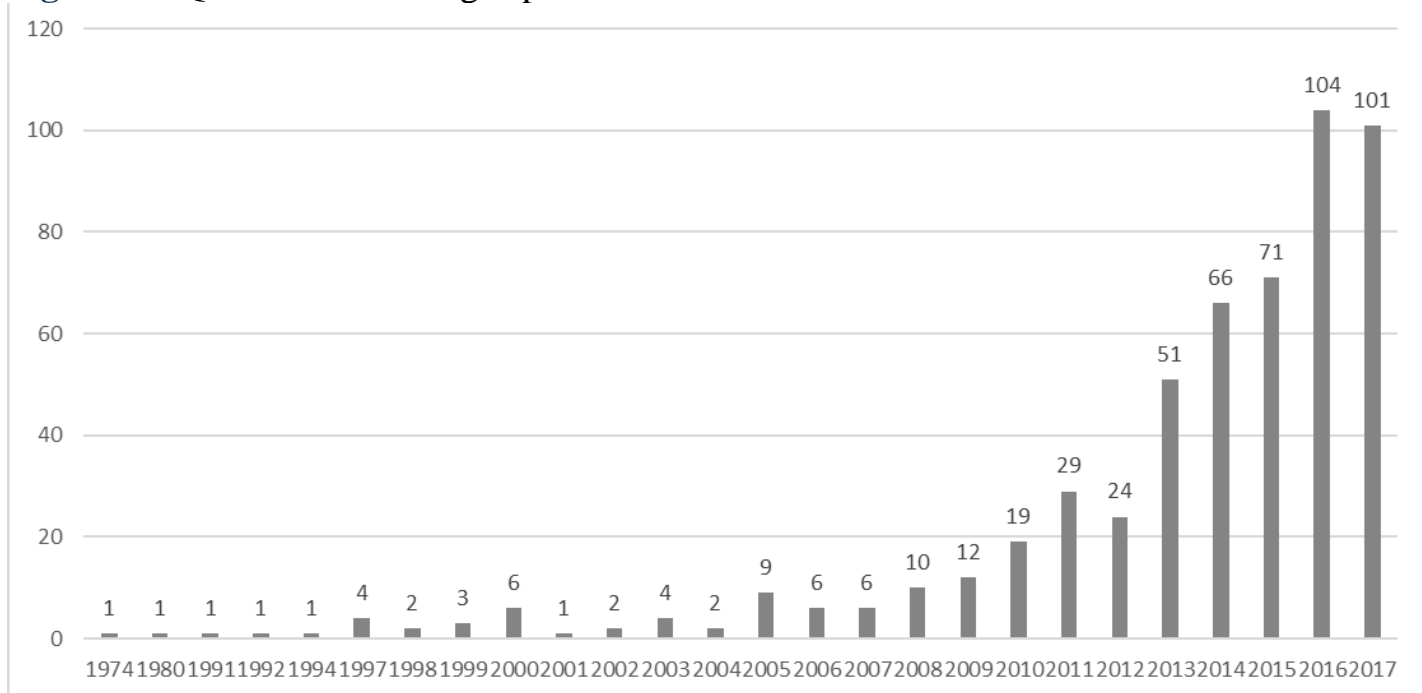

Fonte: Elaborada pelos autores.

Embora o trabalho seminal em lógicas institucional seja o escrito por Friedland e Alford (1991), identificamos um trabalho nos resultados que é de 1974 e que usa o termo ordens institucionais. Nash (1974) utiliza o sistema de ordens interdependentes, no caso ordem normativa e institucional - que, neste trabalho, assemelha-se mais a criação de identidade frente às pressões institucionais externas e internas (Greenwood et al., 2011; Reay \& Hinings, 2009) - para explicar o ambiente institucional complexo de um sindicato de profissionais do setor hospitalar americano. De qualquer modo, vale reforçar o peso do trabalho de Friedland e Alford (1991), pois novos trabalhos sobre o tema, nesta amostra, só viriam a ser publicados novamente em 1997.

A teoria institucional está fortemente relacionada aos estudos organizacionais. Assim, era de se esperar que houvesse uma forte presença de estudos sobre lógicas institucionais em periódicos mais relacionados a esta temática. Esta forte presença em estudos organizacionais é percebida pela quantidade de trabalho nos periódicos Organization Studies, periódico com mais trabalhos sobre lógicas institucionais, e Organization Science. No entanto, conforme a Figura 3, podemos perceber que os trabalhos dentro desta temática estão bem distribuídos entre os principais periódicos da área. Inclusive, em periódicos mais generalistas, como Academy of Management Journal e Journal of Management Studies. Apesar de haver vários artigos em periódicos de administração, há também uma publicação considerável em periódicos de sociologia. 
Figura 3 - Periódicos que mais publicaram

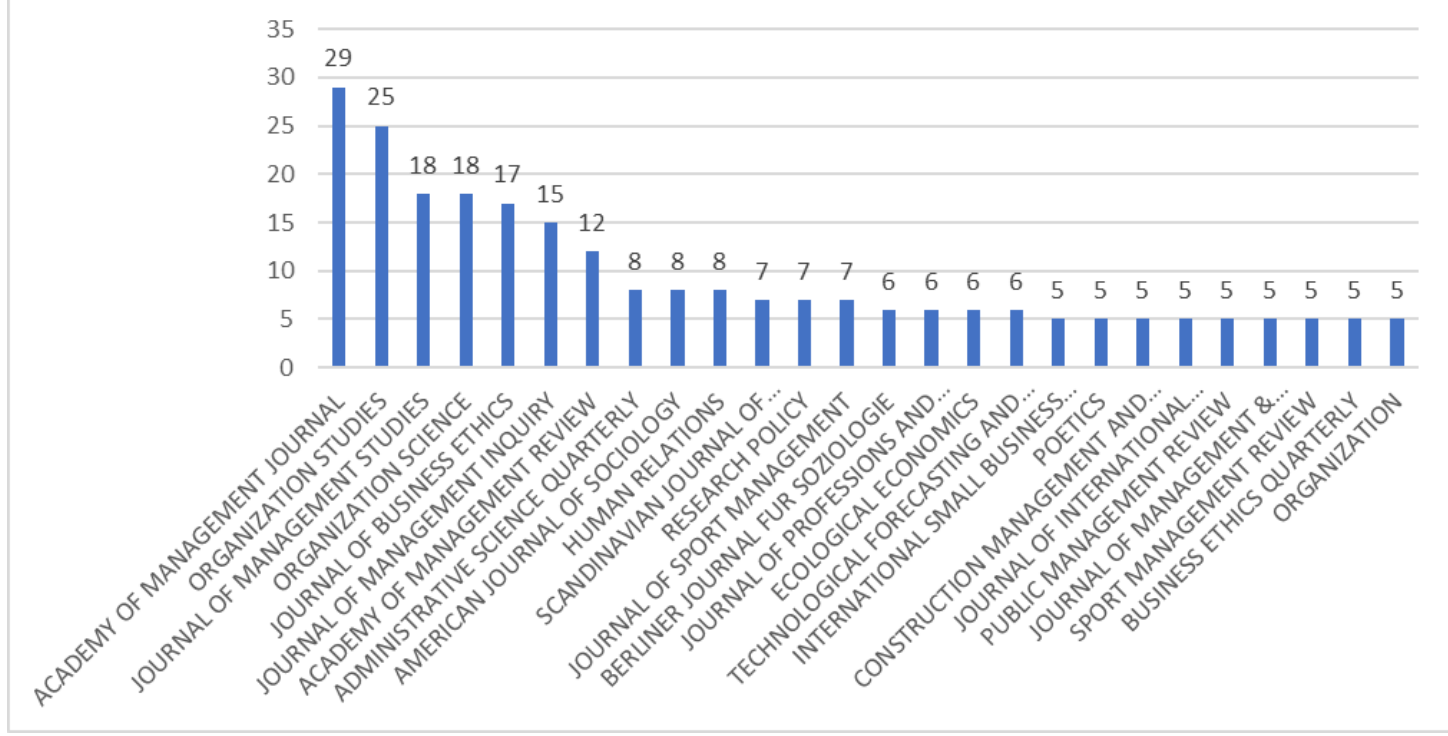

Fonte: Elaborada pelos autores.

O estudo sobre a influência das lógicas institucionais pode ser analisado também pela grande quantidade de trabalhos publicados no Academy of Management Journal, que é um periódico cujo foco são estudos empíricos. Ou seja, há uma forte formação de um corpo relacionado a lógicas institucionais, pois há um consistente aumento de estudos teóricos (Academy of Management Review e Academy of Management Annals), acompanhado pelo aumento de estudos empíricos. Isso indica que o campo ainda está em maturação e que deve ser fortalecida por mais estudo empíricos.

\subsection{Evolução do tema}

O foco da análise de referências citadas neste artigo é o pareamento bibliográfico, no entanto, realizou-se uma breve análise de cocitação para entender como o tema evoluiu ao longo do tempo e quais foram as bases teóricas que fundamentaram esta evolução. Para esta análise, foi construída uma matriz de cocitação com os trabalhos citados pelos artigos da base que possuíam, no mínimo, 30 citações. Esta matriz possuía 77 trabalhos, porém 7 foram retirados por serem obras de método, o que resultou em uma matriz de cocitação com 70 trabalhos.

A Figura 4 apresenta o resultado desta análise de cocitação. Foi utilizado o software BibExcel para a confecção de matriz de cocitação e ordenação das obras por ano. Posteriormente, o próprio BibExcel foi utilizado para criar o arquivo de rede e suas partições. Este arquivo foi visualizado no Pajek e exportado para ser gerado no Vos Viewer. O software Vos Viewer foi utilizado para gerar uma melhor visualização dos dados e criar os clusters. Nesta visualização, cada cor representa um cluster, cada ponto, uma obra e as linhas representam a ligação entre as obras presentes na amostra. Além disso, o tamanho do círculo da figura indica a força da relação daquela obra com as demais e a espessura das linhas, a força daquela relação específica. 
Identifica-se, na Figura 4, que o tema se divide apenas em dois grupos e que esta divisão é clara ao longo do tempo. De modo geral, pode-se dizer que o primeiro grupo, o grupo vermelho, refere-se a artigos representantes do neoinstitucionalismo e suas bases. O segundo grupo, o verde, trata dos trabalhos sobre lógicas institucionais e suas evoluções.

O eixo central da figura mostra ainda a própria evolução da teoria institucional, pois os trabalhos iniciais de Berger e Luckmann (1966) e Giddens (1984) tratam de como a realidade social é construída. Os trabalhos no eixo central de Meyer e Rowan (1977) a Suchman (1995), com exceção de Giddens (1984), tratam de como a realidade social, ou estruturas sociais, se mantêm e se replicam. Partindo de Greenwood e Hinings (1996), os trabalhos focam-se mais em como as instituições mudam ou atuam na mudança das organizações.

Figura 4 - Rede de cocitação - Lógicas Institucionais

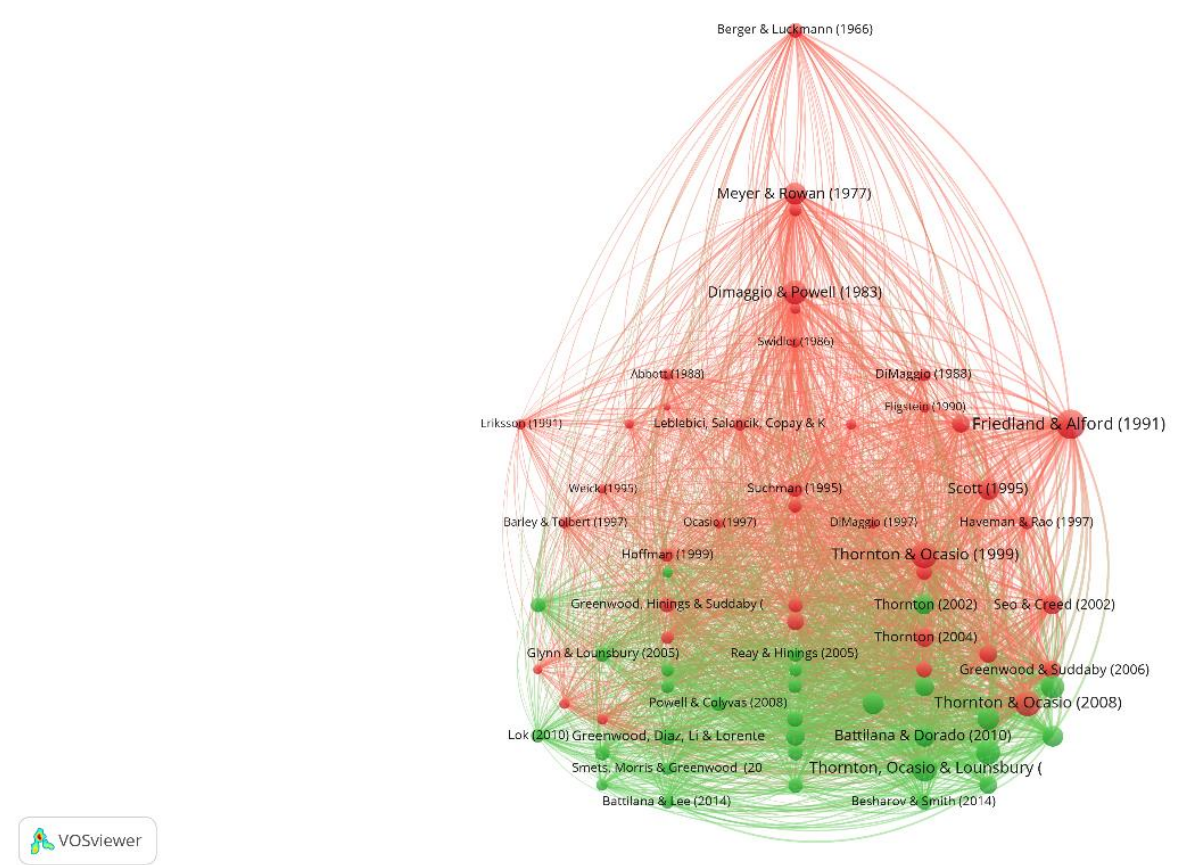

Fonte: Elaborada pelos autores.

Embora o eixo central reflita as principais bases conceituais, os artigos seminais para lógicas institucionais se encontram no lado direito da Figura 4. Pela figura, percebe-se que Friedland e Alford (1991) é o trabalho seminal sobre o tema. Na verdade, isto é colocado também por Thornton et al. (2012). Além desses dois trabalhos, vale destacar Greenwood et al. (2011), que explora o conceito de complexidade institucional, conceito que, de certo modo, retoma a discussão sobre como a realidade social é construída socialmente e influencia, de forma variada, cada ator. Na complexidade institucional, há diversas lógicas, divergentes e convergentes, influenciando, de forma variada, os atores.

A presença do neoinstitucionalismo pode ser percebida também ao analisarmos os trabalhos mais citados. Na Tabela 1, há indícios que reforçam as lógicas institucionais como um campo que descende do neoinstitucionalismo (Thornton \& Ocasio, 2008; Thornton et al., 2012). No entanto, nota- 
se que já está se formando um corpo de pesquisa próprio, pois, das dez obras mais citadas, apenas três se enquadram como obras do neoinstitucionalismo. Todas as outras já fazem parte do corpo de teorias mais recentes, que evoluíram do neoinstitucionalismo.

Tabela 1 - Trabalhos mais citados

\begin{tabular}{|c|c|c|c|c|c|}
\hline Posição & Trabalho & Citações & Posição & Trabalho & Citações \\
\hline 1 & Friedland \& Alford (1991) & 265 & 11 & Battilana \& Dorado (2010) & 110 \\
\hline 2 & Thornton \& Ocasio (1999) & 203 & 12 & Pache \& Santos (2010) & 102 \\
\hline 3 & Thornton \& Ocasio (2008) & 189 & 13 & Kraatz \& Block (2008) & 98 \\
\hline 4 & DiMaggio \& Powell (1983) & 188 & 14 & Pache \& Santos (2013) & 95 \\
\hline 5 & Thornton et al. (2012) & 185 & 15 & Thornton (2002) & 94 \\
\hline 6 & Meyer \& Rowan (1977) & 154 & 16 & Seo \& Creed (2002) & 93 \\
\hline 7 & Scott (2014) & 153 & 17 & Thornton (2004) & 91 \\
\hline 8 & Greenwood et al. (2011) & 148 & 18 & Dunn \& Jones (2010) & 86 \\
\hline 9 & Lounsbury (2007) & 128 & 19 & Marquis \& Lounsbury (2007) & 84 \\
\hline 10 & Reay \& Hinings (2009) & 127 & 20 & Oliver (1991) & 77 \\
\hline
\end{tabular}

Fonte: Elaborada pelos autores.

A Tabela 1 também corrobora a ideia que as lógicas sejam uma das fontes de conexão entre o velho e o neoinstitucionalismo esperado por Selznick (1996). As lógicas retomam o tema de como as organizações se mobilizam e se estruturam para responder às expectativas externas, algo presente em Selznick (1949), inclusive tratando dos conflitos internos e de poder na criação de identidades que respondem às expectativas externas (Durand \& Jourdan, 2012; Edman, 2016a; Greenwood et al., 2011; Reay \& Hinings, 2009) e que respondem a questões sobre isomorfismo e decoupling (Bitektine \& Haack, 2015; Delbridge \& Edwards, 2013; Kodeih \& Greenwood, 2014)

\subsection{Pareamento bibliográfico}

Como colocado anteriormente, o pareamento bibliográfico permite visualizar estágios ainda iniciais de um campo em evolução (Jarneving, 2007). Para a composição da rede mostrada na Figura 5, foram selecionados os trabalhos, na base de dados final, que tinham, no mínimo, dez referências em comum, o que resultou em uma amostra com 300 artigos. A matriz de co-ocorrência foi construída pelo 
BibExcel e a construção dos clusters foi feita com a utilização do algoritmo do próprio software, conforme Person et al. (2009). Entretanto, a visualização e indicação final dos clusters foi realizada com o uso do VosViewer.

Figura 5 - Mapa Pareamento Bibliográfico

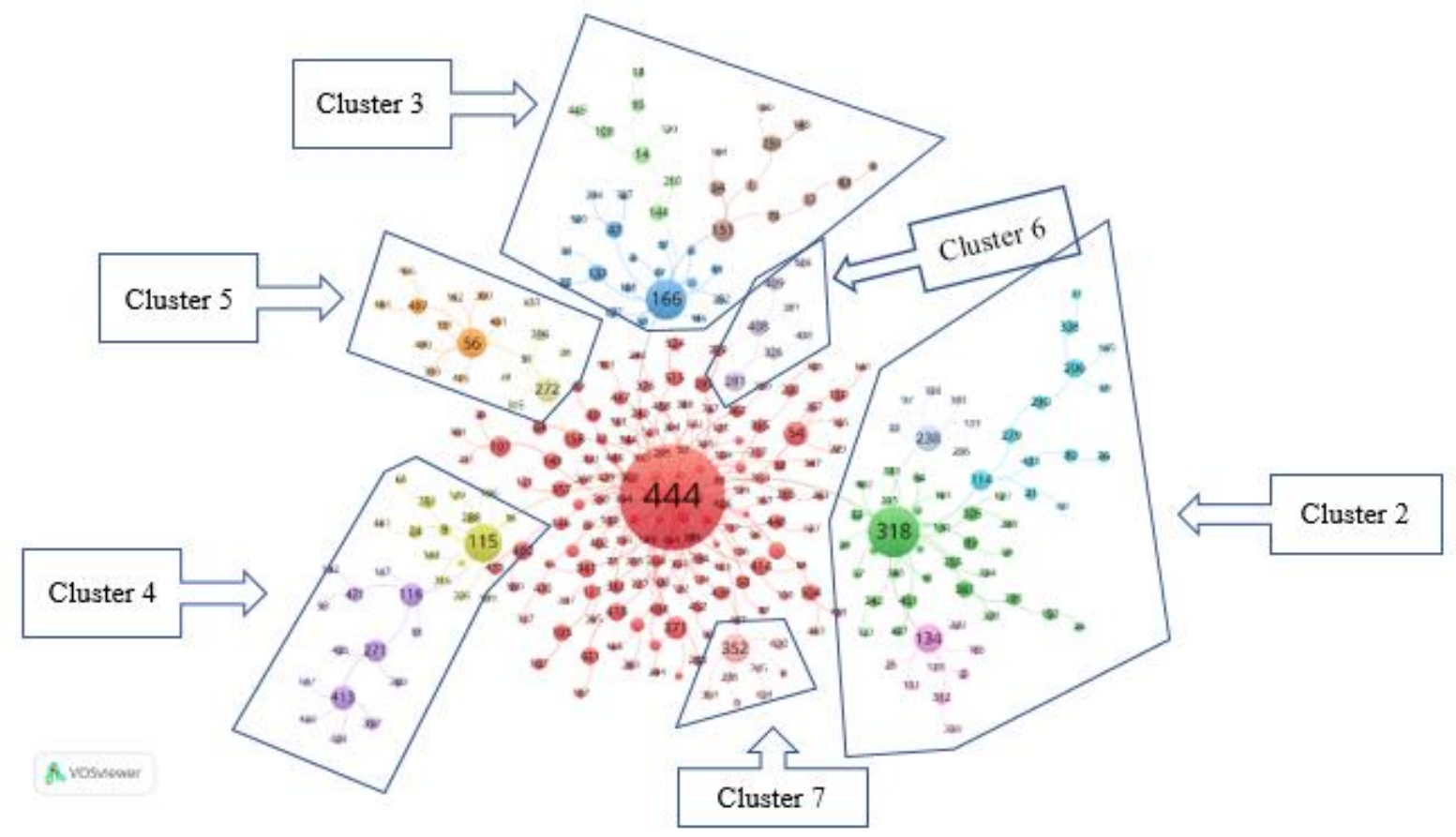

Fonte: Elaborada pelos autores.

As cores na Figura 5 indicam os clusters identificados no VosViewer, num total de 14 clusters. No entanto, em uma segunda análise, podemos considerar que há 7 grandes clusters, com suas ramificações. Deste modo, a Tabela 2 indica quais são os clusters, suas ramificações e quais os artigos centrais neles contidos.

Tabela 2 - Clusters Pareamento e artigos centrais

\begin{tabular}{|c|l|l|c|}
\hline Cluster & \multicolumn{1}{|c|}{ Tema } & \multicolumn{1}{|c|}{ Artigo Central } & \multicolumn{1}{|c|}{ ID } \\
\hline 1 & Complexidade Institucional & Greenwood et al. (2011) & 444 \\
\hline 2 & Pluralismo e Hibridização & Besharov e Smith (2014) & 318 \\
\hline $2 \mathrm{a}$ & Hibridização e Governança/Conformidade & $\begin{array}{l}\text { Smets, Jarzabkowski, Burke e Spee } \\
(2015)\end{array}$ & 238 \\
\hline $2 \mathrm{~b}$ & Hibridização e Identidade & Ocasio e Radoynovska (2016) & 114 \\
\hline $2 \mathrm{c}$ & Hibridização e negócios sociais & Dalpiaz, Rindova e Ravasi (2016) & 134 \\
\hline 3 & Lógicas Institucionais e Empreendedorismo & York, Hargrave e Pacheco (2016) & 166 \\
\hline $3 \mathrm{a}$ & Lógicas Institucionais e Negócios Familiares & $\begin{array}{l}\text { Jaskiewicz, Heinrichs, Rau e Reay } \\
(2016)\end{array}$ & 144 \\
\hline
\end{tabular}




\begin{tabular}{|c|l|l|c|}
\hline $3 \mathrm{~b}$ & $\begin{array}{l}\text { Lógicas Institucionais e Empreendedorismo } \\
\text { Social/Ambiental }\end{array}$ & York, O’Neil e Sarasvathy (2016) & 151 \\
\hline 4 & Complexidade Intra-institucional & Meyer e Höllerer (2016) & 115 \\
\hline $4 \mathrm{a}$ & Retórica e Coupling/Decoupling & Misangyi (2016) & 116 \\
\hline 5 & Lógicas Institucionais e Legitimação & Martí (2017) & 272 \\
\hline $5 \mathrm{a}$ & $\begin{array}{l}\text { Lógicas Institucionais, Mudança e } \\
\text { Empreendedorismo Institucional }\end{array}$ & Joseph, Ocasio e McDonnell (2015) & 56 \\
\hline 6 & Lógicas Institucionais e Governança & 281 \\
\hline 7 & $\begin{array}{l}\text { Lógicas Institucionais, Prática e Discussões } \\
\text { Conceituais }\end{array}$ & Cloutier e Langley (2013) & 352 \\
\hline
\end{tabular}

Fonte: Elaborada pelos autores.

\subsubsection{Análise Cluster 1-Complexidade Institucional}

O cluster 1 da Figura 5 é o maior e possui 138 artigos, ou $46 \%$ da amostra. Podemos considerar, inclusive, os demais clusters como ramificação deste. Deste modo, é difícil indicar uma única palavra que defina este cluster. Porém, nesta tentativa de agrupar os resultados, optou-se pelo termo complexidade institucional. Ao nomear o tema do cluster 1 como complexidade institucional, a palavra complexidade adota mais de um sentido, pois pode e refere-se ao conceito de complexidade institucional proposto por Greenwood et al. (2011). Assim, adota-se que complexidade institucional é a pluralidade de lógicas institucionais com as quais as organizações confrontam-se no campo institucional em que atuam e que, muitas vezes, indicam prescrições incompatíveis entre si. Esta pluralidade pode indicar à organização respostas incompatíveis entre si.

Complexidade institucional também pode se referir, neste caso, como a própria tentativa de classificação. Assim, o título do cluster assume um aspecto metalinguístico, pois o cluster em si é complexo, seja pelos conceitos associados a lógicas institucionais, seja pela variedade de formas pelas quais este contexto foi estudado de forma empírica.

Este ambiente de complexidade institucional não leva apenas a mudanças institucionais, sendo que Kodeih e Greenwood (2014) estudam o papel da identidade organizacional nas respostas das organizações em um ambiente de complexidade institucional. Neste estudo, os diversos atores presentes no campo, em seus diversos níveis, sinalizam quais são os aspectos da identidade institucional e quais lógicas afetam estes aspectos. Deste modo, a identidade institucional é variada e não responde, nem é percebida, por meio de uma única lógica institucional, mas pela relação entre as lógicas e suas influências sobre os atores presentes no campo, sendo a resposta organizacional uma interpretação das ações das organizações interpretadas pelos atores presentes no campo, à luz das influências das diversas lógicas sobre estes. 
É importante entender o papel dos atores nestes estudos, sejam indivíduos ou organizações. Por meio das lógicas, é possível entender como estas impactam as ações individuais e como as ações individuais promovem ou atuam na mudança institucional. Isto é válido, pois um dos pressupostos da complexidade institucional é que as diversas lógicas institucionais atuam de forma diferenciada, tanto em sua composição quanto em intensidade das lógicas. Cada um dos diversos atores presentes no campo gera uma diversidade de comportamentos guiados por uma diversidade de interesses e este é o principal motor das mudanças institucionais (Battilana et al., 2009; Thornton et al., 2012).

Em alguns estudos deste cluster, as lógicas institucionais são as variáveis independentes que explicam fenômenos não tão exclusivos da teoria institucional, por exemplo, a busca e estratégia de inovação de empresas jovens de instrumentos cirúrgicos em Pahnke et al. (2015). Outro exemplo é a pesquisa de Greve e Zhang (2017), que estudaram como a relação entre as antigas lógicas do estado socialista e as novas lógicas de mercado capitalista influenciam as decisões em fusões e aquisições chinesas, indicando que, apesar de lógicas concorrentes, ambas continuam coexistindo e orientando as decisões das organizações. Assim, este primeiro cluster, que chamamos de complexidade institucional, tem artigos que representam os outros clusters. Pelo seu tamanho, este cluster de complexidade institucional, é muito difuso e não apresenta outro denominador comum do que a própria complexidade institucional. Sendo assim, sua diferença em relação aos outros clusters do pareamento são os conceitos que os outros artigos adotam junto com complexidade institucional e os elementos empíricos destes artigos.

\subsubsection{Análise Cluster 2 - Pluralismo e Hibridização}

Neste segundo cluster, o tema central ainda é a complexidade institucional, porém, neste caso, a resposta das organizações a esta complexidade são formas de hibridizar lógicas. Ou seja, o termo complexidade, muitas vezes, é trocado nestes cluster por pluralidade de lógicas. Este termo reflete uma maior possibilidade de diálogo entre as lógicas que compõem o campo institucional no qual a organização está presente.

A hibridização de lógicas pode ser definida como as ações da organização que refletem duas lógicas divergentes e que são centrais a própria organização (Besharov \& Smith, 2014). Assim, os artigos deste cluster, e seus subgrupos, são variações de como as organizações combinam lógicas divergentes, seus efeitos e estratégias.

Neste cluster, há um foco maior no indivíduo, que faz sentido ao pensarmos que a hibridização de lógicas ocorre por meio das percepções das lógicas pelos atores. Neste caso, a agência é fundamental no processo de percepção das lógicas e respostas ao ambiente (Besharov \& Smith, 2014). A agência dos atores se manifesta justamente em perceber as lógicas divergentes isoladamente, tanto nas lógicas quanto nos comportamentos e práticas associadas a elas (Smets et al., 2015). 
Outro fator que retoma a importância do indivíduo é o papel da cognição. Nos estudos mais recentes, tanto a interpretação do campo e suas lógicas institucionais, quanto a construção de novas práticas e aceitação destas, dependem dos aspectos cognitivos e emotivos dos atores envolvidos. Por exemplo, o compartilhamento de aspectos emotivos pode facilitar o engajamento e comprometimento dos atores envolvidos, em contexto de complexidade institucional, no processo de criação de uma nova lógica (Fan \& Zietsma, 2017).

Besharov e Smith (2014) explicam este movimento para a hibridização de lógicas com a importação de práticas de uma lógica para a outra, gerando novas práticas e novas expectativas de práticas e, consequentemente, legitimando novas formas organizacionais e inovações. Na verdade, a inovação vem de lógicas derivadas de lógicas em nível da sociedade, que são combinadas, gerando novas práticas. Nestes casos, as lógicas em nível da sociedade não são, necessariamente, divergentes (Besharov \& Smith, 2014). No entanto, quando divergentes, em contexto de hibridização de lógicas, estas novas lógicas podem gerar heterogeneidade de práticas (Ocasio \& Radoynovska, 2016) e inovações, bem como novos critérios para legitimação de novas inovações (Jay, 2013).

Este cluster, ao estar mais relacionado à hibridização de lógicas, de certo modo, retoma o papel das lógicas institucionais como elemento para explicar as mudanças, uma vez que a hibridização não pressupõe a permanência. No entanto, como acontece esta mudança, ainda não está claro se hibridização é uma resposta a mudança ou fonte desta (Besharov \& Smith, 2014). Na verdade, ambos os casos podem ser encontrados: a hibridização pode ser uma resposta à complexidade institucional (Ocasio \& Radoynovska, 2016), ou as mudanças serem consideradas após a hibridização (Jay, 2013).

\subsubsection{Análise Cluster 3 - Lógicas Institucionais e Empreendedorismo}

O Cluster 3, conforme a Figura 5, é composto de duas ramificações e é o segundo cluster mais numeroso. Novamente, como todos os clusters presentes na amostra, temos que pensar que este também está dentro do conceito de complexidade institucional. Além disso, complexidade institucional está mais relacionada ao empreendedorismo, seja aquele mais ligado a empresas e negócios familiares, seja ao empreendedorismo social e ambiental.

A hibridização é muito presente neste cluster. No entanto, os atores e o contexto são bem específicos, relacionados aos empreendedores e empreendedorismo social e ambiental. Percebe-se que as lógicas, ao nível social em que estão sendo hibridizadas, ou gerando lógicas novas, são as lógicas de mercado, lógicas de família e lógicas de comunidade. Por exemplo, em York, Hargrave et al. (2016), artigo central deste cluster, há hibridização de lógicas de mercado e lógicas ambientais. Embora estejamos chamando esses termos de lógicas ambientais, podemos considerar as lógicas ambientais, ou sociais, como um desdobramento das lógicas de comunidade (Thornton et al., 2012). Assim, podemos considerar que a ramificação principal deste cluster trate mais da hibridização de lógicas, num contexto 
envolvendo a lógica de comunidade e suas derivações, com as outras lógicas, sejam elas de mercado (Carlsson-Wall, Kraus, \& Messner, 2016; York, Hargrave, et al., 2016), de Estado (Vickers, Lyon, Sepulveda, \& McMullin, 2017) ou familiar (Lampel, Bhalla, \& Ramachandran, 2017).

Para York, Hargrave et al. (2016), autores do artigo central de todo este cluster s a hibridização de lógicas ocorre na evolução do campo de energia eólica no Colorado. Neste caso, retoma o conceito de união das lógicas incompatíveis entre si ao nível social, gerando novas práticas, especificamente, lógicas relacionadas a práticas ambientais. Este estudo também mostra esta construção como um processo recursivo, no qual mudanças no campo geram diferentes resposta organizacionais, que geram novas mudanças e novas resposta, até que a lógica central, e seus atores, mudem o campo, sedimentando a aceitação da nova lógica e suas práticas.

No primeiro cluster, derivado do cluster principal, o foco é mais direcionado para as empresas familiares. Apesar do foco serem as empresas familiares, conceitualmente o cluster mantém a temática de como lógicas ao nível social afetam, de forma conjunta, as organizações, gerando novas práticas, por meio de novas lógicas, que são resultado da hibridização de lógicas ao nível social. Em Reay, Jaskiewicz e Hinings (2015), por exemplo, estuda-se como as lógicas familiar, mercado e comunidade influenciam as empresas familiares. Nesse caso, a combinação das três lógicas e suas variadas influências nas empresas presentes no campo gera uma diversidade de práticas, todas elas legitimadas e reconhecidas pelo campo. Justamente pela influência do campo, a lógica de comunidade desempenha função especial na criação e hibridização destas lógicas, pois, enquanto as lógicas familiares e mercado possam ser divergentes em muitos aspectos, a lógica de comunidade é convergente com ambas em diversos aspectos, intermediando, desta forma, o diálogo entre as outras duas lógicas.

O papel da lógica de comunidade pode ser encontrado no segundo cluster derivado. Este cluster aborda os negócios sociais e, assim, está muito relacionado ao empreendedorismo. Na verdade, neste caso, o empreendedorismo exerce o papel de agente que facilita a relação entre lógicas divergentes. A percepção da tensão entre as lógicas, de comunidade e mercado, por meio dos empreendedores sociais, é um elemento fundamental no processo de criação de novas lógicas, por meio da hibridização das lógicas citadas (Wry \& York, 2017).

\subsubsection{Análise Cluster 4 - Complexidade Intrainstitucional, Retórica, Coupling/Decoupling}

O cluster 4 também aborda o tema de complexidade institucional. Na verdade, os artigos na amostra apontam que não há como considerar as lógicas institucionais fora deste contexto. Mesmo porque as lógicas institucionais abrem possibilidades para estudar a mudança e esta mudança ocorre por meio da relação entre as lógicas sobre os atores, indivíduos e organizações, sendo que a variação de práticas e significados são gerados pela percepção dos atores destas lógicas (Battilana et al., 2009; Thornton et al., 2012). Porém, diferentes dos outros clusters, neste, o foco é a relações das lógicas 
geradas, ou presentes em uma lógica institucional em nível social, ou em uma mesma ordem institucional (Friedland \& Alford, 1991).

Analisando a hibridização dentro de uma mesma ordem institucional, Meyer e Höllerer (2016) analisam como prescrições divergentes podem emergir dentro de uma mesma ordem institucional. No caso, esta complexidade intrainstitucional emerge devido aos contextos culturais, nos quais uma mesma organização pode atuar, apesar de uma mesma ordem estar presente nestes contextos. Para responder a esta complexidade, as organizações enviam sinais ambíguos, por meio de seus discursos, de modo que os atores presentes nas variações da lógica institucional não conseguem interpretar completamente as respostas da organização. Assim, esta ambiguidade é uma forma de neutralizar a complexidade intrainstitucional.

Embora a análise do discurso e vocabulário seja importante neste cluster, há um importante artigo que utiliza método quantitativo. Na verdade, a maior parte dos artigos sobre lógicas institucionais são qualitativos. Ashraf, Ahmadsimab e Pinkse (2017) analisam como a complexidade intrainstitucional afeta a sobrevivência de parcerias entre empresas de setores diferentes. Nesse estudo, a incompatibilidade de lógicas entre os parceiros é mitigada pelo grau de interdependência entre os recursos das organizações. Assim, quanto maior é esta interdependência, menor a possibilidade de dissolução desta parceria devido à incompatibilidade entre lógicas.

O cluster derivado do cluster principal apresenta maior foco na comunicação. Além disso, retoma também o decoupling sob a óptica da complexidade institucional. Nesta óptica, a adoção de práticas (coupling) e a não adoção de práticas (decoupling) prescritas por uma mesma lógica são analisadas pelo discurso associado ao motivo de adoção, ou não, e as empresas não adotam, nem ignoram, todas as práticas (Misangyi, 2016). Tal achado vai ao encontro da definição de que as lógicas não afetam os atores da mesma forma, nem na mesma intensidade (Thornton et al., 2012).

O significado dessas práticas, para os autores envolvidos, é fundamental para sua adoção. Neste sentido, o vocabulário exerce um importante papel. O uso do vocabulário, as palavras isoladas e suas relações com outras palavras promovem um compartilhamento de conhecimento e significado entre os atores. Nesse compartilhamento, não apenas o uso de mesmas palavras, mas o uso de mesmas palavras em conjunto, referem-se a categorias e estas transmitem o significado (Loewenstein et al., 2012) e geram as narrativas que darão significado às práticas, por meio do uso desses vocabulários específicos e em formas específicas (Ocasio, Loewenstein, \& Nigam, 2015).

\subsubsection{Análise Cluster 5 - Legitimidade e Empreendedorismo Institucional}

Neste cluster, em sua rede principal, é tratada a legitimidade e o processo de legitimação dentro do contexto de complexidade institucional. Na rede derivada, é abordado o empreendedorismo institucional. Embora a legitimidade seja um elemento chave em teoria institucional, sua relação com o 
empreendedorismo institucional é um pouco diferente. O empreendedorismo institucional busca, ou acontece, por meio da mudança radical dos elementos que garantem a legitimidade, permitindo que aconteçam mudanças divergentes que mudam a relação de poder e posição entre os atores do campo (Battilana et al., 2009).

$\mathrm{O}$ artigo central deste cluster trata de como o processo de legitimação atua em nível micro e macro dentro do campo institucional, sendo processo de legitimação guiado do nível macro para o micro em ambientes de mudança. Porém, em processos de mudança institucional, a contestação ao processo de legitimação vai do micro para o macro e, uma vez que o este processo ocorra, feedbacks positivos moldam a nova ordem institucional, fortalecendo a mudança (Bitektine \& Haack, 2015). Este processo mantém um elemento recursivo, porém reconhece a briga por poder entre os atores e o nível de consciência de ações deliberadas dos mesmos. Sendo assim, este processo se aproxima do realismo crítico (Archer, Bhaskar, Collier, Lawson, \& Norrie, 1998; Fleetwood, 2014), além da estruturação (Giddens, 1984).

A mudança nos elementos que garantem legitimidade e seus efeitos é o tema do cluster derivado deste cluster principal. Esta mudança é representada, principalmente, pelo empreendedorismo institucional, mudança institucional na qual um ator, ou grupo de atores, contestam, desconstroem, mudam e dão novos significados a crenças, práticas e identidades baseadas na lógica institucional dominante (Battilana et al., 2009; Leca \& Naccache, 2006; Martí, 2017).

A complexidade institucional tem um fator determinante para a ação de empreendedores institucionais. Isso ocorre porque o pressuposto da sociedade composta por ordens institucionais interdependentes afetam os atores, de forma variada, em grau de influência e percepção (Friedland \& Alford, 1991; Thornton et al., 2012). Além disso, essas ordens geram lógicas que prescrevem, muitas vezes, significados e comportamentos divergentes (Greenwood et al., 2011). Dessa maneira, esse processo é fundamental para vencer o paradoxo do agente imerso, uma das principais barreiras conceituais na explicação de como um ator pode tentar mudar a instituição que define suas ações (Battilana et al., 2009).

\subsubsection{Análise Cluster 6 - Lógicas Institucionais e Governança}

O processo de legitimação e controle, proposto por Bitektine e Haack (2015), de certo modo, é aplicável a este cluster, mas de forma oposta ao cluster 5. Este cluster aborda como as estruturas de governança atuam para a manutenção das instituições vigentes. Enquanto a mudança acontece do micro para o macro, este cluster descreve a manutenção como uma força que irá do macro para o micro, sendo que os atores em posição de controle utilizam o controle da estrutura para manter seu poder frente às novas lógicas (Joseph et al., 2014). 
A complexidade institucional ainda atua como um conceito subjacente a estes estudos, pois a maior parte deles parte da resposta dos atores em posição dominante no campo, frente à mudança gerada pela entrada, ou alterações, nas lógicas institucionais. Por exemplo, Jansson (2013) estuda o papel da mídia como elemento de transmissão das pressões das lógicas institucionais mais relacionadas à governança corporativa e às respostas dos CEOs frente a estas pressões. $\mathrm{Na}$ verdade, a própria mídia atua como um elemento que diz aos CEOs se eles estão alinhados ou não com as práticas. Porém, isto não gera, necessariamente, uma mudança de comportamento, pois a mesma mídia, devido ao poder dos CEOs, pode ser usada para divulgar as próprias ações destes. Essa ocorrência gera mais liberdade aos líderes, permitindo que ajam em decoupling com algumas das prescrições das estruturas de governança (Bednar, 2012), ou ainda, que usem a mídia para apresentar outros critérios de avaliação de suas ações que não sejam os mesmos propostos pela governança (Westphal \& Park, 2012).

\subsubsection{Análise Cluster 7 - Lógicas Institucionais, Prática e Discussões Conceituais}

Neste último cluster, há dois temas que ganham destaque: a relação das lógicas institucionais com a prática e a discussão das lógicas institucionais sobre outras lentes metateóricas. Metodologicamente, nos trabalhos encontrados em outros clusters, há muita análise sobre a comunicação, seja a fala, por meio de entrevistas e observações, ou análises de dados secundários. Além disso, é adotada a recursividade, baseada na estruturação, como metateoria. Neste cluster, no entanto, há uma preocupação maior com os objetos e tecnologias geradas por meio da influência das lógicas na prática (Cloutier \& Langley, 2013). Nesse mesmo artigo, os autores sugerem o uso de pressupostos etimológicos e ontológicos provenientes do pragmatismo francês, como forma de contribuir para a explicação sobre a recursividade associada à teoria institucional e aos estudos em lógicas institucionais.

O pragmatismo francês também está presente em Patriotta, Gond e Schultz (2011), como explicação alternativa para a manutenção da legitimidade por meio das ordens de valor. Embora haja diferenças, esta outra forma se assemelha às ordens interinstitucionais de Friedland e Alford (1991) e à visão estratificada da realidade, proposta pelo pragmatismo francês para explicar recursividade (Cloutier \& Langley, 2013). Dessa forma, é uma alternativa à estruturação (Giddens, 1984), mas também uma possibilidade de proposta ao realismo crítico (Leca \& Naccache, 2006; Reed, 2009).

\section{Discussão}

Com base nos dados observados, podemos afirmar que o campo das lógicas institucionais ainda está em desenvolvimento e, por isso, oferece diversas oportunidades de pesquisa, sendo a primeira, a oportunidade da realização de estudos de revisão. Estes estudos, como análises bibliométricas, indicam lacunas e sugestões de temas que melhor possam contribuir para evolução do tema (Zupic \& Čater, 
2015). Por estar presente em toda ação, prática e discurso, o tema Lógica Institucional é muito amplo e oferece espaço para estudos como este, que buscam delimitá-lo melhor.

É possível perceber que a definição de lógicas institucionais ora se mostra como um elemento macro em relação as categorias (Ocasio et al., 2015), ora se torna sinônimo das próprias categorias que constrói (Ansari et al., 2013; Rao et al., 2003). Anterior a esta indefinição, há própria confusão sobre uma hierarquia entre lógicas. Às vezes, as lógicas são sinônimas das ordens institucionais (Friedland \& Alford, 1991) e, na maior parte das vezes, apresentam-se como elementos derivados destas ordens. Percebem-se estas diferenças no próprio conceito de complexidade institucional, de forma mais ampla, abarcando tanto ordens interinstitucionais e lógicas institucionais derivadas (Greenwood et al., 2011), como conceitos de complexidade intrainstitucional, nos quais a complexidade ocorre dentro de lógicas derivadas dentro da mesma ordem (Meyer \& Höllerer, 2016). Ao considerar a sociedade como o local no qual estas lógicas se encontram, inter-relacionam-se e dão significado às práticas do dia a dia, ao contrário do neoinstitucionalismo, as lógicas institucionais mostram ainda um grande potencial para estudar as mudanças e inovações.

Seria esperado que a indefinição ocorresse na diferenciação entre os clusters identificados nesta pesquisa (que usou pressupostos etimológicos e ontológicos), visto que as lógicas institucionais, por sua natureza e quase onipresença, mostram-se de várias formas. No entanto, ao analisarmos profundamente os clusters, percebemos muito mais semelhanças entre eles do que diferenças. Por exemplo, pode-se considerar o cluster de hibridização como resposta possível às questões propostas no cluster de complexidade institucional. Na verdade, a hibridização parte de uma variante ontológica em relação ao cluster 1, pressupondo-se que as lógicas não são necessariamente rivais e podem ser combinadas. Mais do que isso, essas lógicas podem ser complementares e integradas. Além disso, ao nível ontológico, a hibridização considera a agência dos atores, tanto em níveis micro como macro, no processo de interpretar as lógicas e considerar a hibridização na formulação de sua resposta a estas expectativas institucionais. Esta forma é levantada como possibilidade de estudos futuros em Greenwood et al. (2011). Entretanto, mesmo em estudos do cluster 1 que levantam esta possibilidade (Lee \& Lounsbury, 2015), colocam-se que algumas lógicas são tão pervasivas no campo que os atores não podem exercer sua agência.

Estes limites não muito definidos acontecem também em relação ao cluster de mudança institucional. Na verdade, a questão da mudança está intrínseca às lógicas institucionais, pois esta é justamente um dos principais pontos de novidade em relação ao neo-institucionalismo (Thornton \& Ocasio, 2008; Thornton et al., 2012). No entanto, apesar de o cluster 1 ser muito difuso, por meio do seu artigo central, podemos considerar que o processo de atender às expectativas de um campo com múltiplas lógicas leva as organizações a mudarem. Em certa medida, os outros clusters mostram como este mesmo campo, repleto das mesmas lógicas e diversos atores, faz que com que as lógicas se transformem. No entanto, devido à recursividade, não fica claro o mecanismo acerca de quem modifica quem. 
Tanto o primeiro quanto o quinto cluster retomam discussões antigas da teoria institucional. $\mathrm{O}$ primeiro cluster, em contraponto ao neoinstitucionalismo, mostra que a criação de identidades frente a demandas institucionais nem sempre resulta em comportamentos isomórficos, pois reconhece as capacidades, estruturas e atores internos a cada organização como elementos que geram variabilidade na resposta a estas pressões institucionais. Inclusive, este tipo de resposta, ajustada a diversas pressões internas, também não se aproxima do decoupling, pois não gera certo mal-estar por não se estar cumprindo uma demanda e porque a resposta não está, necessariamente, alinhada a questões de eficiência organizacional, como colocado por Boxenbaum e Jonsson (2008) e Meyer e Rowan (1977). Tais respostas estão, sim, alinhadas aos interesses de diversos grupos com variados níveis de poder dentro e fora da organização (Bascle, 2016; Fisher, Kotha, \& Lahiri, 2016). Por usa vez, o cluster 5 retoma, de certo modo, a questão do agente imerso - ver Battilana (2006) e Battilana et al. (2009) - e reforça a visão de que um campo com pluralidade de lógicas afeta, de formas variadas, os atores e a replicação de práticas dentro deste campo. Sendo assim, sob esta variedade de percepções, tem-se uma das formas de gerar mudança institucional e fugir do paradoxo do agente imerso.

Como já dito, a mudança é um tema muito relacionado às lógicas institucionais e, com base nos artigos pesquisados, há ainda espaço para estudo de elementos ligado à mudança, porém em nível mais empírico. Por exemplo, apesar de haver vários estudos relacionados à mudança, há poucos trabalhos sobre a inovação em si. Por exemplo, em nenhuma das figuras que apresentam as palavras que compõem os clusters aparece a palavra inovação. Um dos motivos é que a maior parte dos estudos ainda estão focados na mudança ao nível institucional, não em seus reflexos ao nível micro e aos objetos materiais e tecnologias do dia a dia, gap apontado em Cloutier \& Langley (2013). Além disso, há estudos que apontam a inovação como uma resposta à complexidade institucional (Vickers et al., 2017) e o processo de criação e lançamento destas inovações dentro do contexto de complexidade institucional (Pahnke et al., 2015). Entretanto, há poucos estudos que analisam como a complexidade influencia a legitimação das inovações, ou ainda, como as inovações, como materialização das lógicas e mudanças institucionais, influenciam as próprias lógicas dentro do processo recursivo.

Além da complexidade institucional, o conceito de hibridização de lógicas esteve presente em quase todos os clusters. Com base nos artigos da amostra, podemos inclusive diferenciar a complexidade institucional da complexidade intrainstitucional (Meyer \& Höllerer, 2016). A diferença para o segundo caso é que a hibridização acontece com lógicas da mesma ordem institucional. Inclusive, em relação à complexidade institucional proposta por Greenwood et al. (2011), a complexidade intrainstitucional pode ser mais permissiva nos critérios de legitimidade, permitindo que os atores difiram em determinado grau dos comportamentos esperados (Ashraf et al., 2017).

A hibridização de lógicas, pensamento sob o ponto de vista de legitimidade, pode atuar como um elemento que facilite a aceitação de inovações. Inclusive, por gerar mudanças nos significados, discursos e práticas, as lógicas institucionais estão muito relacionadas à inovação que afeta todos os tipos de inovação, conforme o manual de Oslo (Manual, 2005). A hibridização de lógicas pode gerar 
importação de práticas entre as lógicas hibridizadas (York, Hargrave, et al., 2016), fazendo com as práticas, significados e objetos materiais gerados sejam reconhecidos por mais grupos. Este reconhecimento facilita o processo de legitimação (Besharov \& Smith, 2014) e alimenta a heterogeneidade de práticas dentro do mesmo campo (Ocasio \& Radoynovska, 2016).

Além das questões relacionadas à complexidade institucional e à hibridização, os clusters 4 e 5 tratam da retórica, comunicação e mudanças divergentes dentro do campo institucional. No entanto, enquanto o cluster 4 trata de mudanças mais convergentes ou que, pelo menos, não rompam tanto com o status quo, o cluster 5 traz mudanças mais divergentes, que mexem profundamente nas relações de poder dentro do campo. Inclusive, dentre do cluster 5 é que menciona-se o processo de reinstitucionalização (Kim, Shin, Oh, \& Jeong, 2007), ou seja, pressupõe-se uma desinstitucionalização de alguma prática ou lógica, seguida pela reinstitucionalização da nova prática. Apesar deste processe de reinstitucionalização, algo que, no exemplo citado, foi coordenado pelo ator com mais poderes no campo, normalmente há desinstitucionalização de práticas e alteração da configuração de poder dentro do campo, que é conduzido pelos empreendedores institucionais. (Battilana et al., 2009)

Ainda em uma tentativa de relacionar lógicas institucionais com inovação, e pensando nesta mudança da configuração do campo institucional, é possível que a ação de empreendedores institucionais esteja relacionada com a inovação disruptiva, uma vez que esta muda a configuração e estruturas dos atores no campo (Christensen, 1997). Na verdade, assim como na mudança institucional, inovações também podem ser geradas após a ação de empreendedores institucionais, porém não há muitos estudos sobre o tema. Além disso, devido à recursividade do processo de mudanças institucionais, não está claro se mudanças feitas por empreendedores institucionais podem ser frutos de inovações disruptivas ou se as inovações disruptivas são frutos das mudanças institucionais.

Além da inovação, há uma forte relação das lógicas institucionais com estratégia. No cluster 6 , percebemos que as lógicas institucionais definem, inclusive, o critério de avaliação dos CEOs e também das organizações (Westphal \& Park, 2012). Além disso, sobre o papel da legitimidade, sendo as lógicas um dos definidores dos critérios de legitimação (Bitektine \& Haack, 2015), quanto maior legitimidade, maior liberdade para inovar, mas também maior quantidade de acesso aos recursos presentes no campo (Greenwood et al., 2011; Suchman, 1995).

Identificamos também que há uma forte ligação das lógicas institucionais com diversos elementos da estratégia. Isto está presente no próprio conceito de mudanças institucionais, sejam internas ou ao nível do campo, que levam às mudanças na forma de legitimidade, o que vai mudar o acesso das organizações aos recursos (Bitektine \& Haack, 2015; Meyer \& Rowan, 1977). Esta familiaridade também está presente no cluster 6 , ao tratar da forma como grupos com poder utilizam a pluralidade de lógicas para responder, de forma variada, às diversas pressões institucionais, conforme seus interesses. Por este enfoque, mais relacionado ao poder, pode haver uma primeira impressão relacionada a estudos organizacionais, que é verdadeira. Porém, ainda há espaço para a utilização da teoria do alto escalão (Hambrick \& Mason, 1984) ou da teoria da agência (Jensen \& Meckling, 1976), 
para analisar como são construídas estas estruturas de governança. Essas teorias podem conciliar os interesses destes diversos públicos, sendo que as lógicas institucionais podem ser consideradas elementos que exercem pressão institucional, no caso, tanto normativa como coercitiva.

Sobre a relação das lógicas institucionais com estratégia, há espaço maior para diálogos entre lógicas institucionais e Resource Based View (RBV). Percebemos um alinhamento com a RBV, no sentido de que a escolha da criação de identidade, na hibridização de lógicas e mudança institucional, é feita para buscar mais legitimidade. Tal ação gera acesso a mais recursos por parte da organização. A RBV vai dizer quais acessos a recursos específicos e quais formas de mobilizá-los podem garantir vantagem competitiva para a organização (Barney, 1991). Neste caso, a habilidade de compreender as demandas decorrentes das lógicas e a forma de mesclar as lógicas na criação de sua identidade pode ser sim um recurso que gere vantagem competitiva. Esta linha de estudo já foi proposta em Greenwood et al. (2011) e desenvolvida, de certo modo, por Battilana e Dorado (2010), Bitektine e Haack (2015) e Fisher et al. (2016).

Os quinto e sétimo clusters tratam mais abertamente da relação entre estrutura e agência e novas formas de estudar as lógicas institucionais, respectivamente. Esses clusters estão alinhados com as possibilidades de que as lógicas institucionais abrem os estudos organizacionais, sendo que eles também abrem espaço para mais um diálogo possível com o campo da estratégia e inovação, pois retomam a visão das teorias de ecologia sobre as organizações. Tais teorias foram muito importantes no início dos estudos em estratégia (Nerur et al., 2008) e ainda podem lançar novos ideias ao aliar as lógicas e os campos institucionais. Neste caso, abre-se espaço para estudos sobre como o campo institucional escolhe as melhores formas organizacionais com base nas pressões das lógicas presentes. De certo modo, o próprio isomorfismo mimético pode ser considerado como uma pressão ambiental das formas mais adaptadas ao ambiente. Além disso, a importância da pressão externa e em diferentes campos pode ser vista em estudos relacionados às lógicas institucionais e aos negócios internacionais (Edman, 2016a, 2016b). Neste caso, a organização cria variações de identidades específicas para os locais nos quais atua, porém, estas identidades atuarão como menores, de modo a não haver conflitos com sua identidade principal.

De modo geral, este trabalho contribui para o estudo das lógicas institucionais em três sentidos. Primeiro, pelo fato de que este é um campo em evolução, mostrando as oportunidades de estudos e as áreas mais estruturadas. É possível perceber que o campo das lógicas institucionais carece de mais estudos para haver mais delimitação e clareza entre as bases teóricas que o compõem. Inclusive, nesta primeira análise, podemos dizer que há uma área mais madura dentro de lógicas institucionais, referente ao estudo das identidades como resposta à complexidade institucional. Identifica-se, ainda, que há campos mais emergentes, como a hibridização e categorização como forma de mudança institucional.

A segunda contribuição desta pesquisa mostra espaço para unir o estudo das lógicas institucionais e da inovação. Seja por meio do estudo do processo da criação da inovação (KoskelaHuotari, Edvardsson, Jonas, Sörhammar, \& Witell, 2016), mas também pela influência das lógicas 
institucionais no lançamento e aceitação das inovações, tema pouco explorado diretamente, pois há apenas o pressuposto da mudança institucional, não de seus impactos ao nível mais tangível (Battilana \& Casciaro, 2012; Malsch \& Gendron, 2013). Isso ocorre porque há uma carência de estudos sobre elementos mais materiais, como tecnologias e objetos, derivados das lógicas institucionais (Cloutier \& Langley, 2013). Assim, abre-se espaço para estudo de patentes, tecnologias e produtos frutos da complexidade institucional.

Para outras áreas, há contribuição desta pesquisa ao indicar que os estudos em estratégia estão mais relacionados a lógicas institucionais. Isto abre oportunidades, não somente ao propor o diálogo com teorias mais maduras no campo da estratégia, mas também por trazer elementos e fenômenos comuns à estratégia para serem estudos sob o ponto de vista das lógicas institucionais. Dentre estes elementos, já foram citados aqui a teoria do alto escalão e a tomada de decisão, sendo que há outras possibilidades, desde o acompanhamento, de modo mais objetivo, do alinhamento da identidade e seu reflexo no desempenho da organização, até a consideração das lógicas institucionais como elementos que direcionam as tomadas de decisão da organização, inclusive sob o ponto de vista da estratégia como prática.

Por último, sob o ponto de vista metodológico, este trabalho contribui por utilizar uma técnica pouco aplicada em bibliometrias da área da Administração, que é o pareamento bibliográfico. Dentre os trabalhos bibliométricos com destaque na área, a maior parte utiliza técnicas baseadas em citações e cocitações. Deste modo, este trabalho visa contribuir reforçando o papel de mais uma ferramenta útil para analisar a produção nos estudos em administração.

\section{Conclusão}

Buscou-se, por meio deste trabalho, compreender melhor como as lógicas institucionais se estruturam como campo de pesquisa em administração e quais são as oportunidades de pesquisa neste campo. Esta pesquisa reforçou que este é um campo em evolução. Na verdade, as lógicas institucionais herdam o momentum e o caráter evolutivo que é próprio da teoria institucional, que se transformou do velho institucionalismo para o neoinstitucionalismo e, agora, abre espaço para estudos com o foco nas lógicas institucionais, que também continuam a se transformar. Para um campo relativamente jovem, as lógicas institucionais já possuem interessantes ramificações, que demandam mais estudos para ganhar forma e corpo.

Além dos pontos citados acima, sob o ponto de vista do método, há a possibilidade de estudos futuros justamente no sentido de definição de melhores desenhos destas árvores genealógicas entre o neoinstitucionalismo e as lógicas institucionais. Deste modo, estudos que combinem análise de cocitação dentro do campo das lógicas institucionais e pareamento bibliográfico, aplicado à teoria institucional subdivida em períodos, podem explicar melhor esta evolução e proporem temas que 
busquem preencher espaços neste caminho evolutivo. Além disso, devido ao fato de a maior parte dos estudos em lógicas institucionais serem qualitativos, revisões sistemáticas podem indicar caminhos para abordagens quantitativas.

Como limitação do estudo, há o fato deste trabalho ter tido como fonte de dados a base Web o Science. Poder-se-ia ampliar a quantidade de referências que sustentam a análise, por meio de outras bases importantes, tais como a Scopus da Elsevier, principalmente, porque a base Scopus oferece maior quantidade de resultados frequentemente (Bergman, 2012). Ainda que algumas análises como, por exemplo, a publicação por países, possa ter resultados bastante semelhantes (Archambault et al., 2009), há outros resultados que podem ser diferentes, porque a cobertura de ambos difere para estudos bibliométricos (Mongeon \& Paul-Hus, 2016). De fato, muitas referências com alta quantidade de citações não estão incluídas em ambas as bases, em publicações de Ciências Sociais (Martín-Martín et al., 2018). Mais profundamente, ainda há críticas ao uso dessas bases, indicando-se o uso de bases nacionais (no caso do Brasil, a mais adequada para Administração seria a Spell) ou bases específicas de áreas do conhecimento (Mongeon \& Paul-Hus, 2016).

\section{Referências}

Almandoz, J. (2014). Founding Teams as Carriers of Competing Logics: When Institutional Forces Predict Banks' Risk Exposure. Administrative Science Quarterly, 59(3), 442-473. https://doi.org/10.1177/0001839214537810

Archambault, É., Campbell, D., Gingras, Y., \& Larivière, V. (2009). Comparing bibliometric statistics obtained from the Web of Science and Scopus. Journal of the American Society for Information Science and Technology, 60(7), 1320-1326. https://doi.org/10.1002/asi.21062

Archer, M., Bhaskar, R., Collier, A., Lawson, T., \& Norrie, A. (1998). Critical Realism: Essential Readings. Routledge. https://doi.org/10.1163/156920601794750701

Ashraf, N., Ahmadsimab, A., \& Pinkse, J. (2017). From Animosity to Affinity: The Interplay of Competing Logics and Interdependence in Cross-Sector Partnerships. Journal of Management Studies, 54(6), 793-822. https://doi.org/10.1111/joms.12273

Bascle, G. (2016). Toward a Dynamic Theory of Intermediate Conformity. Journal of Management Studies, 53(2), 131-160. https://doi.org/10.1111/joms.12155

Battilana, J., \& Casciaro, T. (2012). Change agents, networks, and institutions: A contingency theory of organizational change. Academy of Management Journal, 55(2), 381-398. https://doi.org/10.5465/amj.2009.0891

Battilana, J., Leca, B., \& Boxenbaum, E. (2009). How actors change institutions: Towards a theory of institutional entrepreneurship. Academy of Management Annals, 3(1), 65-107. https://doi.org/10.1080/19416520903053598

Battilana, J., \& Lee, M. (2014). Advancing Research on Hybrid Organizing - Insights from the Study of Social Enterprises. The Academy of Management Annals, 8(1), 397-441.

https://doi.org/10.1080/19416520.2014.893615 
Bednar, M. K. (2012). Watchdog or Lapdog? A Behavioral View of the Media as a Corporate Governance Mechanism. Academy of Management Journal, 55(1), 131-150. https://doi.org/10.5465/amj.2009.0862

Berger, P. L., \& Luckmann, T. (1966). The social construction of reality: A treatise in the sociology of knowledge. New York: Anchor Books.

Bergman, E. M. L. (2012). Finding citations to social work literature: The relative benefits of using Web of Science, Scopus, or Google Scholar. The Journal of Academic Librarianship, 38(6), 370379. https://doi.org/10.1016/j.acalib.2012.08.002

Besharov, M. L., \& Smith, W. K. (2014). Multiple institutional logics in organizations: Explaining their varied nature and implications. Academy of Management Review, 39(3), 364-381. https://doi.org/10.5465/amr.2011.0431

Bitektine, A., \& Haack, P. (2015). The "macro" and the "micro" of legitimacy: Toward a multilevel theory of the legitimacy process. Academy of Management Review, 40(1), 49-75. https://doi.org/10.5465/amr.2013.0318

Boxenbaum, E., \& Jonsson, S. (2008). Isomorphism, diffusion and decoupling. In R. Greenwood, C. Oliver, R. Suddaby, \& K. Sahlin (Eds.), The SAGE Handbook of Organizational Institutionalism (pp. 78-98). London: Sage Publications Ltd.

Bromley, P., \& Powell, W. W. (2012). From Smoke and Mirrors to Walking the Talk: Decoupling in the Contemporary World. The Academy of Management Annals, 6(1), 483-530. https://doi.org/10.1080/19416520.2012.684462

Carlsson-Wall, M., Kraus, K., \& Messner, M. (2016). Performance measurement systems and the enactment of different institutional logics: Insights from a football organization. Management Accounting Research, 32, 45-61. https://doi.org/10.1016/j.mar.2016.01.006

Christensen, C. M. (1997). Innovator's Dilemma: When New Technologies Cause Great Firms to Fail. Harvard Business Review Press.

Cloutier, C., \& Langley, A. (2013). The Logic of Institutional Logics: Insights From French Pragmatist Sociology. Journal of Management Inquiry, 22(4), 360-380. https://doi.org/10.1177/1056492612469057

Currie, G., \& Spyridonidis, D. (2016). Interpretation of Multiple Institutional Logics on the Ground: Actors Position, their Agency and Situational Constraints in Professionalized Contexts. Organization Studies, 37(1), 77-97. https://doi.org/10.1177/0170840615604503

Dalpiaz, E., Rindova, V., \& Ravasi, D. (2016). Combining Logics to Transform Organizational Agency. Administrative Science Quarterly, 61(3), 347-392. https://doi.org/10.1177/0001839216636103

Delbridge, R., \& Edwards, T. (2013). Inhabiting institutions: Critical realist refinements to understanding institutional complexity and change. Organization Studies, 34(7), 927-947. https://doi.org/10.1177/0170840613483805

Dimaggio, P. J., \& Powell, W. W. (1983). The Iron Cage Revisited: Institutional Isomorphism and Collective Rationality in Organizational Fields. American Sociological Review, 48(2), 147-160. https://doi.org/10.2307/2095101 
Dunn, M. B., \& Jones, C. (2010). Institutional Logics and Institutional Pluralism: The Contestation of Care and Science Logics in Medical Education, 1967-2005. Administrative Science Quarterly, 55(1), 114-149. https://doi.org/10.2189/asqu.2010.55.1.114

Durand, R., \& Jourdan, J. (2012). Jules or Jim: Alternative conformity to minority logics. Academy of Management Journal, 55(6), 1295-1315. https://doi.org/10.5465/amj.2011.0345

Edman, J. (2016). Cultivating Foreignness: How Organizations Maintain and Leverage Minority Identities. Journal of Management Studies, 53(1), 55-88. https://doi.org/10.1111/joms.12129

Fan, G. H., \& Zietsma, C. (2017). Constructing a Shared Governance Logic: The Role of Emotions in Enabling Dually Embedded Agency. Academy of Management Journal, 60(6), 2321-2351. https://doi.org/10.5465/amj.2015.0402

Fisher, G., Kotha, S., \& Lahiri, A. (2016). Changing with the Times: An Integrated View of Legitimacy and New Venture Life Cycles. Academy of Management Review, 41(3), 383-409. https://doi.org/10.5465/amr.2013.0496

Fleetwood, S. (2014). Bhaskar and critical realism. In P. Adler, P. du Gay, G. Morgan, \& M. Reed (Eds.), The Oxford Handbook of Sociology, Social Theory and Organization Studies. Oxford: Oxford University Press.

Friedland, R., \& Alford, R. R. (1991). Bringing society back in: Symbols, practices, and institutional contradictions. In W. W. Powell \& P. J. DiMaggio (Eds.), The New Institutionalism in Organization Analysis. Chicago: The University of Chicago Press.

Giddens, A. (1984). The constitution of society: Outline of the theory of structure. Berkeley.

Glanzel, W., \& Czerwon, H. J. (1996). A new methodological approach to bibliographic coupling and its application to the national, regional and institutional level. Scientometrics, 37(2), 195-221. https://doi.org/10.1007/BF02093621

Greenwood, R., Diaz, A. M., Li, S. X., \& Lorente, J. C. (2010). The Multiplicity of Institutional Logics and the Heterogeneity of Organizational Responses. Organization Science, 21(2), 521-539. https://doi.org/10.1287/orsc.1090.0453

Greenwood, R., \& Hinings, C. R. (1996). Understanding Radical Organizational Change: Bringing together the Old and the New Institutionalism. The Academy of Management Review, 21(4), 1022. https://doi.org/10.2307/259163

Greenwood, R., Raynard, M., Kodeih, F., Micelotta, E. R., \& Lounsbury, M. (2011). Institutional Complexity and Organizational Responses. Academy of Management Annals, 5(1), 317-371. https://doi.org/10.1080/19416520.2011.590299

Greve, H. R., \& Zhang, C. M. (2017). Institutional Logics and Power Sources: Merger and Acquisition Decisions. Academy of Management Journal, 60(2), 671-694. https://doi.org/10.5465/amj.2015.0698

Haveman, H. a. (1993). Follow the Leader: Mimetic Isomorphism and Entry Into New Markets. Administrative Science Quarterly, 38(4), 593. https://doi.org/10.2307/2393338

Jansson, A. (2013). "Real Owners" and "Common Investors": Institutional Logics and the Media as a Governance Mechanism. Corporate Governance: An International Review, 21(1), 7-25. https://doi.org/10.1111/j.1467-8683.2012.00932.x 
Jarneving, B. (2007). Bibliographic coupling and its application to research-front and other core documents. Journal of Informetrics, 1(4), 287-307. https://doi.org/10.1016/j.joi.2007.07.004

Jaskiewicz, P., Heinrichs, K., Rau, S. B., \& Reay, T. (2016). To Be or Not to Be: How Family Firms Manage Family and Commercial Logics in Succession. Entrepreneurship Theory and Practice, 40(4), 781-813. https://doi.org/10.1111/etap.12146

Jay, J. (2013). Navigating Paradox as a Mechanism of Change and Innovation in Hybrid Organizations. Academy of Management Journal, 56(1), 137-159. https://doi.org/10.5465/amj.2010.0772

Joseph, J., Ocasio, W., \& McDonnell, M.-H. (2014). The Structural Elaboration of Board Independence: Executive Power, Institutional Logics, and the Adoption of CEO-only Board Structures in US Corporate Governance. Academy of Management Journal, 57(6), 1834-1858. https://doi.org/10.5465/amj.2012.0253

Kim, T.-Y., Shin, D., Oh, H., \& Jeong, Y.-C. (2007). Inside the Iron Cage: Organizational Political Dynamics and Institutional Changes in Presidential Selection Systems in Korean Universities, 1985-2002. Administrative Science Quarterly, 52(2), 286-323. https://doi.org/10.2189/asqu.52.2.286

Kodeih, F., \& Greenwood, R. (2014). Responding to Institutional Complexity: The Role of Identity. Organization Studies, 35(1), 7-39. https://doi.org/10.1177/0170840613495333

Koskela-Huotari, K., Edvardsson, B., Jonas, J. M., Sörhammar, D., \& Witell, L. (2016). Innovation in service ecosystems-Breaking, making, and maintaining institutionalized rules of resource integration. Journal of Business Research, 69(8), 2964-2971.

https://doi.org/10.1016/j.jbusres.2016.02.029

Lampel, J., Bhalla, A., \& Ramachandran, K. (2017). Family values and inter-institutional governance of strategic decision making in Indian family firms. Asia Pacific Journal of Management, 34(4), 901-930. https://doi.org/10.1007/s10490-017-9509-0

Leca, B., \& Naccache, P. (2006). A Critical Realist Approach To Institutional Entrepreneurship. Organization, 13(5), 627-651. https://doi.org/10.1177/1350508406067007

Lee, M.-D. P., \& Lounsbury, M. (2015). Filtering Institutional Logics: Community Logic Variation and Differential Responses to the Institutional Complexity of Toxic Waste. Organization Science, 26(3), 847-866. https://doi.org/10.1287/orsc.2014.0959

Loewenstein, J., Ocasio, W., \& Jones, C. (2012). Vocabularies and Vocabulary Structure: A New Approach Linking Categories, Practices, and Institutions. Academy of Management Annals, 6(1), 41-86. https://doi.org/10.1080/19416520.2012.660763

Lounsbury, M. (2007). A Tale of Two Cities: Competing Logics and Practice Variation in the Professionalizing of Mutual Funds. Academy of Management Journal, 50(2), 289-307. https://doi.org/10.5465/AMJ.2007.24634436

Malsch, B., \& Gendron, Y. (2013). Re-theorizing change: Institutional experimentation and the struggle for domination in the field of public accounting. Journal of Management Studies, 50(5), 870-899. https://doi.org/10.1111/joms.12006

Manual, O. (2005). The measurement of scientific and technological activities. Proposed Guidelines for Collecting an Interpreting Technological Innovation Data. 
Martí, G. (2017). New Concepts for New Dynamics: Generating Theory for the Study of Religious Innovation and Social Change. Journal for the Scientific Study of Religion, 56(1), 6-18. https://doi.org/10.1111/jssr.12325

Martín-Martín, A., Orduna-Malea, E., \& López-Cózar, E. D. (2018). Coverage of highly-cited documents in Google Scholar, Web of Science, and Scopus: a multidisciplinary comparison. Scientometrics, 116(3), 2175-2188. https://doi.org/10.1007/s11192-018-2820-9

Meyer, J. W., \& Rowan, B. (1977). Institutionalized Organizations: Formal Structure as Myth and Ceremony. American Journal of Sociology, 83(2), 340-363. https://doi.org/10.2307/2778293

Meyer, R. E., \& Höllerer, M. A. (2016). Laying a smoke screen: Ambiguity and neutralization as strategic responses to intra-institutional complexity. Strategic Organization, 14(4), 373-406. https://doi.org/10.1177/1476127016633335

Misangyi, V. F. (2016). Institutional complexity and the meaning of loose coupling: Connecting institutional sayings and (not) doings. Strategic Organization, 1476127016635481-. https://doi.org/10.1177/1476127016635481

Mongeon, P., \& Paul-Hus, A. (2016). The journal coverage of Web of Science and Scopus: a comparative analysis. Scientometrics, 106(1), 213-228. https://doi.org/10.1007/s11192-015-1765-5

Nash, A. (1974). Local 1199, Drug and Hospital Union: An Analysis of the Normative and Institutional Orders of a Complex Organization. Human Relations, 27(6), 547-566. https://doi.org/10.1177/001872677402700602

Ocasio, W., \& Radoynovska, N. (2016). Strategy and commitments to institutional logics: Organizational heterogeneity in business models and governance. Strategic Organization, 1476127015625040-. https://doi.org/10.1177/1476127015625040

Ocasio, William, Loewenstein, J., \& Nigam, A. (2015). How Streams of Communication Reproduce and Change Institutional Logics: The Role of Categories. Academy of Management Review, 40(1), 28-48. https://doi.org/10.5465/amr.2013.0274

OECD and SCImago Research Group (CSIC). (2016). Compendium of Bibliometric Science Indicators. OECD, Paris.

Quevedo-Silva, F., Santos, E. B. A., Brandão, M. M., \& Vils, L. (2016). Estudo bibliométrico: orientações sobre sua aplicação. Revista Brasileira de Marketing, 15(2), 246-262. https://doi.org/10.5585/remark.v15i2.3274

Pahnke, E. C., Katila, R., \& Eisenhardt, K. M. (2015). Who Takes You to the Dance? How Partners' Institutional Logics Influence Innovation in Young Firms. Administrative Science Quarterly, 60(4), 596-633. https://doi.org/10.1177/0001839215592913

Patriotta, G., Gond, J.-P., \& Schultz, F. (2011). Maintaining Legitimacy: Controversies, Orders of Worth, and Public Justifications. Journal of Management Studies, 48(8), 1804-1836. https://doi.org/10.1111/j.1467-6486.2010.00990.x

Person, O., Danell, R., \& Schneider, J. W. (2009). How to use Bibexcel for various types of bibliometric analysis. In F. Åström, R. Danell, B. Larsen, \& J. W. Schneider (Eds.), Celebrating scholarly communication studies: A Festschrift for Olle Persson at his 60th Birthday (pp. 9-24). Leuven: International Society for Scientometrics and Informetrics.

Rao, H., Monin, P., \& Durand, R. (2003). Institutional Change in Toque Ville: Nouvelle Cuisine as an Identity Movement in French Gastronomy. American Journal of Sociology, 108(4), 795-843. 
Ratinaud, P., \& Marchand, P. (2012). No TiApplication de la méthode ALCESTE à de "gros" corpus et stabilité des "mondes lexicaux": analyse du "CableGate" avec IRaMuTeQtle. Actes Des 11eme Journées Internationales d'Analyse Statistique Des Données Textuelles, 835-844.

Reay, T., Jaskiewicz, P., \& Hinings, C. R. (2015). How Family, Business, and Community Logics Shape Family Firm Behavior and "Rules of the Game" in an Organizational Field. Family Business Review, 28(4), 292-311. https://doi.org/10.1177/0894486515577513

Reay, Trish, \& Hinings, C. R. R. (2009). Managing the Rivalry of Competing Institutional Logics. Organization Studies, 30(6), 629-652. https://doi.org/10.1177/0170840609104803

Reed, M. I. (2009). Critical Realism: Philosophy, Method, or Philosophy in Search of a Method? In D. A. Buchanan \& A. Bryman (Eds.), The SAGE Handbook of Organizational Research Methods (pp. 430-448). London: Sage Publications Ltd.

Reinert, M. (1990). Alceste une méthodologie d'analyse des données textuelles et une application: Aurelia De Gerard De Nerval. Bulletin of Sociological Methodology/Bulletin de Méthodologie Sociologique, 26(1), 24-54. https://doi.org/10.1177/075910639002600103

Scott, W. R. (2014). Institutions and Organizations: Ideas, Interests, and Identities (4a). London: Sage Publications Ltd.

Selznick, P. (1949). TVA and the Grass Roots - A Study in the Sociology of Formal Organization. University of California Press Berkeley and Los Angeles.

Selznick, P. (1996). Institutionalism "Old" and "New." Administrative Science Quarterly, 41(2), 270277. https://doi.org/10.2307/2393719

Smets, M., Jarzabkowski, P., Burke, G. T., \& Spee, P. (2015). Reinsurance Trading in Lloyd's of London: Balancing Conflicting-yet-Complementary Logics in Practice. Academy of Management Journal, 58(3), 932-970. https://doi.org/10.5465/amj.2012.0638

Suchman, M. C. (1995). Managing Legitimacy: Strategic and Institutional Approaches. The Academy of Management Review, 20(3), 571. https://doi.org/10.2307/258788

Thijs, B., Zhang, L., \& Glänzel, W. (2015). Bibliographic coupling and hierarchical clustering for the validation and improvement of subject-classification schemes. Scientometrics, 105(3), 1453-1467. https://doi.org/10.1007/s11192-015-1641-3

Thornton, P. H., \& Ocasio, W. (1999). Institutional Logics and the Historical Contingency of Power in Organizations: Executive Succession in the Higher Education Publishing Industry, 1958- 19901. American Journal of Sociology, 105(3), 801-843. https://doi.org/10.1086/210361

Thornton, P. H., \& Ocasio, W. (2008). Institutional Logics. In R. Greenwood, C. Oliver, K. Sahlin, \& R. Suddaby (Eds.), The SAGE Handbook of Organizational Institutionalism (pp. 99-129). London: Sage Publications Ltd.

Thornton, P. H., Ocasio, W., \& Lounsbury, M. (2012). The institutional logics perspective: A new approach to culture, structure and process. Oxford: Oxford University Press.

Tranfield, D., Denyer, D., \& Smart, P. (2003). Towards a methodology for Developing EvidenceInformed Management Knowledge by Means of Systematic Review. British Journal of Management, 14, 207-222. https://doi.org/10.1111/1467-8551.00375

van Eck, N. J., \& Waltman, L. (2010). Software survey: VOS viewer, a computer program for bibliometric mapping. Scientometrics, 84(2), 523-538. https://doi.org/10.1007/s11192-009-0146-3 
Vickers, I., Lyon, F., Sepulveda, L., \& McMullin, C. (2017). Public service innovation and multiple institutional logics: The case of hybrid social enterprise providers of health and wellbeing. Research Policy, 46(10), 1755-1768. https://doi.org/10.1016/j.respol.2017.08.003

Vogel, R., \& Güttel, W. H. (2013). The dynamic capability view in strategic management: A bibliometric review. International Journal of Management Reviews, 15(4), 426-446. https://doi.org/10.1111/ijmr.12000

Westphal, J. D., \& Park, S. H. (2012). Unintended agency: Impression management support as a trigger of institutional change in corporate governance. Research in Organizational Behavior, 32, 23-46. https://doi.org/10.1016/j.riob.2012.10.002

Wry, T., \& York, J. G. (2017). An Identity-Based Approach to Social Enterprise. Academy of Management Review, 42(3), 437-460. https://doi.org/10.5465/amr.2013.0506

York, J. G., Hargrave, T. J., \& Pacheco, D. F. (2016). Converging winds: Logic hybridization in the Colorado wind energy field. Academy of Management Journal, 59(2), 579-610. https://doi.org/10.5465/amj.2013.0657

York, J. G., O’Neil, I., \& Sarasvathy, S. D. (2016). Exploring Environmental Entrepreneurship: Identity Coupling, Venture Goals, and Stakeholder Incentives. Journal of Management Studies, 53(5), 695-737. https://doi.org/10.1111/joms.12198

Zanin, L. M., Nassif, V. M. J., Cunha, J. A. C. da, \& Pedron, C. D. (2015). Aqueles Que Mudam as Regras do Jogo: uma Revisão Sistemática sobre o Empreendedorismo Institucional. In VII Encontro de Estudos em Estratégia 3Es. Brasilia.

Zupic, I., \& Čater, T. (2015). Bibliometric Methods in Management and Organization. Organizational Research Methods, 18(3), 429-472. https://doi.org/10.1177/1094428114562629 